\title{
Has Ayushman Bharat Dwindled the Out-of-Pocket Expenditure?
}

\author{
Renu Bala ${ }^{1}$ Manoj Kumar², K. Kaveri Krishna ${ }^{3}$, Chanam Sonia Devi ${ }^{4}$ \\ ${ }^{1}$ Department of Economics, Indira Gandhi National Open University, New Delhi, India, ${ }^{2}$ Centre for \\ Economic Studies \& Planning, Jawaharlal Nehru University, New Delhi, India, ${ }^{3}$ Operation department, \\ Renewbuy.com, Gurgaon, India, ${ }^{4}$ Department of ACEE, Manipur University, Manipur, India.
}

\section{ABSTRACT}

\section{BACKGROUND}

The Ayushman Bharat scheme claimed to cover all pre-existing ailments and 1,350 medical packages covering day care treatments, medicine, diagnosis, and surgery. We wanted to address the research question of the Pradhan Mantri Jan Arogya Yojana viability in depleting pocket expenses in a rustic terrain of Haryana.

\section{METHODS}

The data of 114 policyholders had been collected through a questionnaire using a convenience sampling technique in the Sirsi and Madanpur village of Haryana. The respondents were asked questions and their responses were recorded in the questionnaires accordingly. All respondents were from the rustic territory of the Karnal district. The collected data was analysed with the usage of descriptive statistics.

\section{RESULTS}

The respondents (18.4 percent) who had sickness, paid for their treatment from their own pockets instead of getting it done under the scheme. The scheme claimed that no empanelled hospital turned-down treatment. Survey acknowledged that private hospitals asked for valid cards of some respondents (8.8 percent). Some family member names were left out from the card, mainly kids under the age of 5 - years. Some respondents were having trouble in getting the card and found no offline application centre for applying.

\section{CONCLUSIONS}

The survey concluded that no policyholder had acknowledged any medical benefits from the scheme. The need is to create more awareness in the families of ailments and remove the hitch in getting the card. Each ailment (from little to fatal) needs to secure to utilize the stipulated claim.

\section{KEY WORDS}

Ayushman Bharat, Government-Funded Health Insurance Scheme, Out-of-Pocket Expenditure, Pradhan Mantri Jan Arogya Yojana
Corresponding Author: Dr. Manoj Kumar Centre for Economic Studies \& Planning, Jawaharlal Nehru University, New Delhi-110067, India.

Email: manojkumar@jnu.ac.in

DOI: $10.14260 / j e m d s / 2021 / 391$

How to Cite This Article:

Bala R, Kumar M, Krishna KK. et al. Has Ayushman Bharat dwindled the out-ofpocket expenditure? J Evolution Med Dent Sci 2021;10(25):1895-1898, DOI: 10.14260/jemds/2021/391

Submission 17-11-2020,

Peer Review 24-04-2021,

Acceptance 30-04-2021,

Published 21-06-2021.

Copyright (C) 2021 Manoj Kumar et al. This is an open access article distributed under Creative Commons Attribution License [Attribution 4.0 International (CC BY 4.0)] 


\section{BACKGROUND}

Medical cover is to fund the medical care costs of an individual. ${ }^{1}$ Indian government focuses on getting universal health coverage. ${ }^{2}$ In 2018, the Ayushman Bharat national health protection mission was endorsed, which was later on renamed as Pradhan Mantri Jan Arogya Yojana. ${ }^{3}$ Haryana state doesn't have any state-funded medical care conspire. Thus, the state is thoroughly relying upon this scheme and this study is examining the ground viability of it, where complete medical care inclusion is lowest. Although, a few states like Kerala, Chhattisgarh, Gujarat, Karnataka, and Tamil Nadu have government funded medical care conspires along with this scheme. As of 14 June 2018, out of 26 states for which data was accessible, an aggregate of 11.97 crore families got secured under either this scheme or state funded medical care schemes. This scheme claimed to incorporate 1,350 medical packages that covered surgery, day care treatments, medicines, diagnosis, all previous ailments, and no empanelled hospital could deny treatment. According to scheme guidelines, costs being controlled by fixing package rates in advance, and hospitals are to be empanelled based on packages. The huge Indian health care expenditure is out of pocket. This study reported reasons behind increasing interest in health insurance and its project history to date. During exploratory fieldwork, 6 - themes suggested for future researches and among them, one was out of pocket expenditure. ${ }^{4}$

In Uttar Pradesh despite both the government funded health insurance schemes (like ESIS, ${ }^{5}$ RSBY$^{1} \& \mathrm{CGHS}^{2}$ ) and non-government funded schemes only 4.8 percent individuals were covered. There is a need to reduce out of pocket expenditure.6 The Rashtriya Swasthya Bima Yojana (RSBY) ${ }^{3}$ proved statistically insignificant in terms of reducing out of pocket expenditure for the poor (in both cases of inpatient \& outpatient). On the contrary, out of pocket expenditure increased by 30 percent. 7 in India. Out of pocket expenditure was around 63 percent of total current health expenditure. In each year, around 5.5 crores of people are becoming poor because of out-of-pocket expenditure. 8 The sustainable development goals (SDG) in 2030 emphasizes that all people need to receive quality health services. Meantime, they need to get it without any financial difficulty. 9 In India, there is a need for extensive reforms in public and private health care providers to meet its stated claims of providing universal health coverage for its population. ${ }^{2}$ The largest part of out-ofpocket expenditure comprised of preventive and outpatient care expenditure. Whereas the scheme covers merely secondary and tertiary hospitalization that would not reduce the out-of-pocket expenses.10 The challenges during the execution of Ayushman Bharat in Bihar (in May 2018 with data of 102 respondents) were lack of mindfulness. As a result, most respondents utilized conventional prescriptions, which did not help treat the element.

After reviewing the earlier studies, it has summed up that out-of-pocket expenditure is a major worry for families as most of them do not have any medical cover. This study analyses the viability of the scheme in tapering off the out-ofpocket expenses in the rustic territory of Haryana that has no other state funded scheme.

\section{METHODS}

It is a descriptive study conducted from December 2019 to December 2020 to depict the impact of the Pradhan Mantri Jan Arogya Yojana in selected sample. Haryana state does not have any state-funded medical coverage schemes. Subsequently this study analyses the viability of this scheme on out-ofpocket expenditure through primary and secondary data.

The primary data was collected through the questionnaire using convenience sampling technique in the Sirsi and Madanpur Village of Haryana. The study was approved by ethical committee. The respondents were asked questions and their responses were recorded accordingly. The survey was led with the help of two school teachers who visited the respondent's families to get the responses. The teachers were filtered (as volunteers) as they taught the families and their children in the primary school in surveyed locality. Meanwhile they were given telephonic instructions (as discussed by the research committee) by the authors to ask the mentioned questions in questionnaire and fill it accordingly. In the first go they didn't get desired data (incomplete response) so the authors instructed for the second round of data collection. The second round collected data was complete and fit for analysis.

\section{Inclusion Criteria}

The respondents who had the the Pradhan Mantri Jan Arogya Yojana's card and the ones who will be eligible for the Yojana's card as per the scheme.

\section{Exclusion Criteria}

The respondents who were not eligible and not taking the Pradhan Mantri Jan Arogya Yojana card.

\section{Statistical Analysis}

The descriptive statistical analysis was carried out in the current study and the results of categorical measurements were reported in the form of frequency and percentage. The statistical analysis was done with SPSS (Statistical Package of Social Sciences, version 22).

\section{RESULTS}

In India, out of pocket expenditure is 62 percent of current health expenditure, which is a major worry for the families and government as well. To minimize the out-of-pocket expenditure with the health insurance schemes has become a major debatable issue. All respondents (100 percent) belonged to a rustic territory of Karnal district. Most of them (75.4 percent) were males, and the rest (24.3 percent) were females. A large part of them ( 96.5 percent) were engaged in agriculture activities, and the rest (3.5 percent) were labourers. They had 4, 5, and more than 5 (36.0, 30.7, and 21.9 percent respectively) family members (Table 2).

Table 1 shows most respondents (99.1 percent) knew the scheme. Though, few of them ( 0.9 percent) were unaware. A large part of the respondents (74.6 percent) said that it was 
expenditure by using the survey method. The significance of health insurance for any country has been shown in achieving the universal health covegae. ${ }^{11}$ The study observed during the survey that this scheme was unable to cover the minor sickness, and that treatment sometimes becomes costly. Respondents' collective statements showed that they appreciated the scheme by saying that it was a good scheme for underprivileged families and reducing the out-of-pocket expenditure.

Though it was also observed that most of them did not utilize their cards because of their unconcern at the initial stage of the diseases, and inadequate diagnostic provisions for the minor sickness. Meanwhile in India, where out-of-pocket expenditure (62 percent of current health expenditure) is a big concern for families and the government; it has become a debatable issue to actually reduce it with the health insurance coverage. For sure PMJAY is a powerful scheme to reduce outof-pocket expenditure, especially for catastrophic expenditure. Therefore, more awareness programs and transparency are required to ensure that each and every family, that is eligible, should register for this scheme.

\section{CONCLUSIONS}

Numerous respondents and their family members (18.5 percent) had different ailments, and for treatment, they were spending from their pocket expenses instead of getting any medical cover. Meanwhile, some respondents (23.7 percent) had deferred their treatment in the absence of consciousness about sickness. Likewise, some respondent's problems in the wake of joining the scheme were under the age of 5 - years and were excluded from the card, and that card was invalid in private clinics / hospitals. Some were confronting trouble in getting the card, and there was no off - line centre to help them out. Consequently, not a single respondent depleted the claim amount (partial or total) under the scheme. It interprets that this scheme did not plunge the out-of-pocket expenses.

The respondents ranked the 4 - parameters (i.e., premium, coverage, reputation, and treatment) of the scheme, most responses (61.4 percent) tuned out gratified with premium payments only. In response to cover, prestige, and treatment (i.e., 51.8, 59.6, and 92.1 percent respectively), they did not utter a word. It means that they spent by themselves on the treatment instead of getting the medical claim under the scheme.

In short, the viability of the government funded scheme to reduce the pocket expenses not verified in the field. There is a need to incorporate all ailments (from a little to lethal) in this scheme. To create mindfulness about sickness from the beginning to treat without delay, and assist families in getting the card on the schedule.
Data sharing statement provided by the authors is available with the full text of this article at jemds.com.

Financial or other competing interests: None.

Disclosure forms provided by the authors are available with the full text of this article at jemds.com.

Authors thank all the respondents for contributing responses and time in this study.

\section{REFERENCES}

[1] Smith JC, Medalia C. Health insurance coverage in the United States: 2013. Current Population Reports 2014 September.

[2] Angell BJ, Prinja S, Gupt A, et al. The Ayushman Bharat Pradhan Mantri Jan Arogya Yojana and the path to universal health coverage in India: overcoming the challenges of stewardship and governance. PLoS Med 2019;16(3):e1002759.

[3] Annual Report 2018-19. Official Website Ayushman Bharat Pradhan Mantri Jan Arogya Yojana. National Health Authority [cited 2021 Apr 15]. https://pmjay.gov.in/node/1131

[4] Ahlin T, Nichter M, Pillai G. Health insurance in India: what do we know and why is ethnographic research needed. Anthropology \& Medicine 2016;23(1):102-24. [cited $2021 \quad$ Apr 15$]$. https://www.tandfonline.com/doi/abs/10.1080/13648 470.2015.1135787

[5] Bakshi H, Sharma R, Kumar P. Ayushman Bharat Initiative (2018): what we stand to gain or lose! Indian J Community Med 2018;43(2):63-6.

[6] Singh P, Kumar V. Insurance coverage under different health schemes in Uttar Pradesh, India. Clinical Epidemiology and Global Health 2017;5(1):33-9.

[7] Karan A, Yip W, Mahal A. Extending health insurance to the poor in India: an impact evaluation of Rashtriya Swasthya Bima Yojana on out of pocket spending for healthcare. Soc Sci Med 2017;181:83-92.

[8] ASSOCHAM. Ayushman Bharat-A big leap towards Universal Health-KPMG India. 2019. https://assets.kpmg/content/dam/kpmg/in/pdf/2019/ 12 /universal-health-coverage-ayushman-bharat.pdf.

[9] WHO. Monitoring report on primary health care on the road to universal health coverage. WHO 2019. [cited 2021 Apr https://www.who.int/healthinfo/universal_health_cover age/report/2019/en/

[10] Devanbu VGC, Ravi H, Taneja N. Pradhan Mantri Jan Arogya Yojana-Ayushman Bharat. Indian Journal of Community Health 2020;32(2):337-40.

[11] Kumar M, Renu B. Health care and health insurance in India: a review based study. In: Innovative SocioEconomic Trends in BFM (Banking, Finance \& Management). Nitya Publication 2019:118-29. 